\title{
Glucocorticoid Resistance in the Upper Respiratory Airways
}

\author{
Fabiana C.P. Valera, Edwin Tamashiro and Wilma T. Anselmo-Lima
}

Additional information is available at the end of the chapter

http://dx.doi.org/10.5772/53105

\section{Introduction}

The nasal mucosa is known to be the first important barrier against inhalants of the respiratory tract. In contrast to initial opinion, this tissue actively interacts with external factors, producing a wide combination of mediators in response to aggressor agents [1]. In this respect, it is easy to understand why the nasal mucosa is predisposed to the development of several chronic inflammatory diseases, with rhinitis and rhinosinusitis being the most common disorders.

According to the ARIA guideline [2], the prevalence of allergic rhinitis has increased in the last years and has been found to be around $25 \%$ in Europe [3]. The prevalence of symptoms related to chronic rhinosinusitis is about $15 \%$ in the USA, being the second most prevalent chronic condition in the American population [4].

The most common and studied cause of chronic rhinitis is allergic rhinitis (AR) [2]. AR is a nasal inflammatory disease in which the allergen induces IgE-mediated inflammation. The mediators released by the nasal mucosa will finally lead to intense inflammatory cell recruitment (predominantly eosinophils) [5], epithelial metaplasia (more pronounced in perennial AR) [6], and noticeable stromal edema, especially due to the action of matrix metalloproteinases [7]. This response to allergens will finally induce the classical symptoms of AR, such as sneezing, itching, nasal discharge and nasal obstruction. These symptoms considerably impair the quality of life, affecting sleep quality, concentration during work/school, and other daily activities [2].

Chronic rhinosinusitis can be subdivided into two forms: chronic rhinosinusitis without nasal polyps (CRSsNP) and with nasal polyps (CRSwNP). These two entities are almost clinically identical, and it is very difficult to differentiate them based only on nasal symptoms [8]. Both forms present variable degrees of facial pain, decreased sense of smell, 
nasal discharge and nasal congestion. Clinically, the differentiation of these two entities is made by the detection of nasal polyps by nasal endoscopy. However, the major differences between CRSsNP and CRSwNP concern histology and molecular biomarkers [9]. CRSsNP is characterized by neutrophil recruitment, light edema, increased remodelling [9] and a Th1subset profile. In contrast, CRSwNP is characterized by an eosinophil recruitment, intense oedema, loose connective tissue and a Th1/Th2 mixed -subset profile, but with remarkable Th2 polarization [8-10].

\section{Cellular and molecular knowledge in nasal inflammatory diseases}

\subsection{Allergic Rhinitis}

The development of signs and symptoms that characterize allergic rhinitis (AR) depends on three events: sensitization to an allergen, degranulation of inflammatory mediators after reexposure to the allergen (early phase) and infiltration of inflammatory cells into the tissue (late phase).

The respiratory nasal mucosa is continuously exposed to several particles that are deposited on the mucous blanket that covers the respiratory epithelium. These antigens are processed by antigen-presenting cells (APCs) such as Langerhans cells, that are later presented to a naïve lymphocyte through a major histocompatibility complex (MHC) class II molecule [11]. For reasons not completely elucidated, naïve lymphocytes (Th0) differentiate into Th2 lymphocytes and produce and release a pool of cytokines characteristic of the Th2 response pattern (IL-3, IL-4, IL-5, IL-9, IL-10, IL-13, GM-CSF). Moreover, the differentiated Th2 lymphocytes stimulate the production of specific IgE by plasmocytes through IL-3 and IL-4, and inhibit the differentiation of Th0 lymphocytes into Th1, as well as its messenger molecules. This selective environment polarized to a Th2 response is typically seen in allergic mechanisms, such as AR, asthma and atopic dermatitis, and in helminthic infections. $B$ cells that recognize the processed antigen and receive appropriate contact signals (CD40CD40) and molecular stimuli (IL-4, IL-6, IL-10, IL-13) start to produce specific IgE. In the presence of continuous antigen stimulation, B-cells switch from the production of a lowaffinity IgE molecule to the production of a high-affinity one [11].

Once high-affinity IgE circulates in the plasma and interstitial fluid, it binds to the Fc receptors. These receptors are present on the surface of mast cells and basophils, and are responsible for activating these cells when exposed to the binomial antibody-pathogen. After mast cells leave the post-capillary venules, they are able to reside in the stroma of the nasal submucosa and intraepithelially, probably by the production of several proteases. Resident mast cells are also able to produce some cytokines related to Th2 polarization (IL-4, IL-5), which in turn can cause an increased cell proliferation and survival time. In allergic mucosa, for instance, mast cells proliferate at a higher rate compared to a non-allergic environment, probably by the effect of Th2 cytokines [12, 13].

In a second phase, after sensitization and priming of resident mast cells with IgE, the respiratory mucosa becomes susceptible to a new exposure. When the specific inspired 
allergen binds to the complex IgE-mediator cell, massive degranulation of allergic molecules (either already existent and newly synthetized) are released in the extracellular compartment. Histamine is the main molecule released and involved in the early phase of symptoms of AR, but other mediators such as leukotriene, bradykinin, prostaglandins, platelet activating factor, and even some proteases (tryptase and chymase) and cytokines (TNF- $\alpha$, IL-4, IL-5) also have a role in the development of allergic symptoms [14]. These mediators lead to the classical early symptoms of sneezing, itching, rhinorrhea, and nasal congestion that occur within a few minutes after allergen exposure (5-30 minutes). These symptoms are the consequence of direct actions of these mediators on different resident cells [15]. Glands are stimulated by leukotrienes and chymases to produce and release mucous secretions. Endothelial cells of post-capillary venules are affected by histamine, bradykinin, platelet activating factor and leukotrienes, inducing vasodilatation, increased vascular permeability and cell adhesion. Peripheral sensory endings are stimulated by histamine type 1 receptors on nociceptive type $C$ fibers that generate an uncomfortable sensation of pain and pressure, sneezing and itching [16]. As the nasal mucosa is constantly assaulted by physical and chemical agents, the disruption of some areas facilitates the exposure of allergens to allergic mediator cells.

After the IgE-mediated inflammatory burst triggered by the allergen, some individuals present total clearance of mediators and have complete resolution of symptoms after some minutes. However, a significant percentage $(60-70 \%)$ of the allergic population develops the late AR response due to the recruitment of inflammatory cells into the nasal mucosa. The increased vascular permeability added to the expression of adhesion molecules (ICAM-1) and production of chemokines, recruits a variety of inflammatory cells that include eosinophils and basophils and, to a lesser extent, neutrophils and other leukocytes.

The late phase typically occurs 4-6 hours after the allergen contact and is clinically represented by the nasal obstruction and congestion caused by mucosal edema. Toxic products of eosinophils, such as eosinophil cationic protein (ECP), major basic protein (MBP), eosinophil-derived neurotoxin and eosinophil peroxidase, are evident during the late phase and are proportional to the eosinophil recruitment. These highly charged proteins bind to proteoglycans and hyaluronic acid and cause cell damage and epithelial detachment. Other important inflammatory mediators involved in the late phase are leukotrienes, histamine, and cytokines of the Th2 response (IL-5, IL-6, GM-CSF) [17, 18]. Interestingly, the recruited eosinophils are able to promote an auto-positive feedback to prolong their survival and recruitment into the tissue, which ultimately leads to an independent eosinophilic inflammation (Figure 1). IL-3, IL-5, and GM-CSF are Th2 cytokines that reduce apoptosis and prolong eosinophil cell survival. Besides, IL-5, eotaxin and RANTES produced by eosinophils and other infiltrated cells recruit even more eosinophils to the inflammatory site, explaining the reason why a chronic allergic inflammation can be seen even when the allergen is not present [19].

Lymphocytes are another group of cells that may play an important role in the late phase of AR. Memory T cells, T-cytotoxic and B cells have been demonstrated to be increased in AR compared to other forms of non-allergic rhinitis and to controls [20]. 


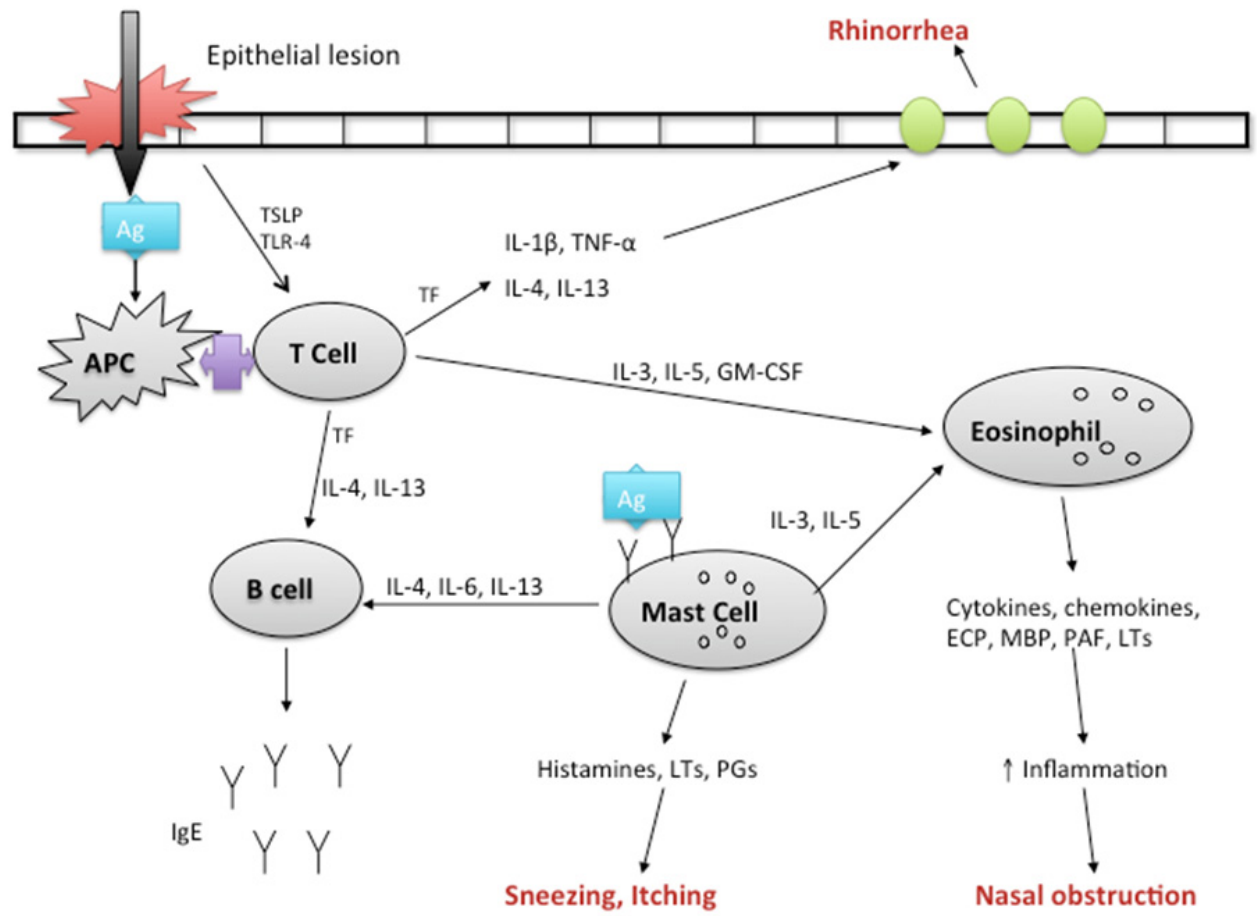

Figure legend: Ag: antigen; APC: antigen presenting cell; TSLP: thymic stromal lymphopoietin; TLR: toll-like receptor; IL: interleukin; TNF: tumor necrosis factor; TF: transcriptor factor; Ig: immunoglobulin; GM-CSF: granulocyte macrophage colony-stimulating factor; LT: leukotriene; PG: prostaglandin; ECP: eosinophil cationic protein; MBP: major basic protein; PAF: platelet activating factor

Figure 1. Cellular and molecular events involved in the early and late phase response of AR. Initially, the antigen invades the cell, and either binds to the APC (antigen presenting cell) or activates innate immune response through TSLP or TLR-4. These mechanisms together will activate adaptative immune response, and T cells are triggered to Th2 response, producing cytokines as IL-4, IL-5 and IL-13. These cytokines will induce epithelial cells to produce rhinorrhea and will recruit inflammatory cells (as eosinophils) to nasal mucosa. Eosinophils will produce several cytokines that will lead to nasal obstruction. B cells are activated and produce IgE, which, among the antigen itself, will induce the mast cell to secrete histamine, leukotrienes and prostaglandins, among others, finally leading to the symptoms of sneezing and itching.

Resident cells may also participate in the late phase and development of chronic allergic inflammation. Nasal epithelial cells express an increased number of pro-inflammatory cytokines such as IL-1 $\alpha$, IL-1 $\beta$, IL-6, IL-8 and GM-CSF in allergic patients [21, 22]. Also, epithelial cells are the main source of thymic stromal lymphopoietin (TSLP) on the nasal mucosa, an important cytokine that drives $\mathrm{T}$ cells to produce Th2 cytokines [23] and is increased in AR patients compared to controls [24]. Submucosal glands located in the lamina propria are substantially increased in allergic patients $(25 \%)$ compared to non-allergic individuals $(15 \%)$, consistent with the chronic state of increased production of nasal secretions [25] 
In summary, the cellular and molecular mechanisms of AR involve B cell production of IgE and mast cell/basophil priming, activation of resident cells, recruitment of inflammatory cells and, in some circumstances, induction of a persistent inflammatory reaction maintained by a positive feedback.

\subsection{Chronic Rhinosinusitis (CRS)}

Chronic Rhinosinusitis (CRS) is clinically defined as the persistence of signs and symptoms such as nasal obstruction, nasal congestion, rhinorrhea, facial pain, cough, and loss of smell for more than 12 weeks, confirmed by nasal endoscopy or computed tomography. It is related to an inflammatory process of the mucoperiosteal pavement of the sinonasal cavity, whose etiology can be clearly defined in a few subgroups of patients, involving mechanical obstruction, immunodeficiency, cystic fibrosis, and ciliary dyskinesia. However, in the majority of cases, the etiology of CRS cannot be determined. Some investigators have raised different hypotheses for the pathogenesis of CRS such as disruption of the epithelial barrier, allergy, exposure to pollutants, maintenance of mucosal inflammation due to underlying osteitis, persistence of bacterial biofilms, and overreaction to staphylococcal superantigens or fungus. It is interesting to note that individually these theories do not apply to all patients but may explain the pathogenicity in some cases. Despite the unrevealed etiopathogenesis, recent advances have been made in the elucidation of the cellular and molecular events involved in different situations of CRS. Based on molecular phenotyping studies, the classification of CRS into two different clinical subsets has been currently accepted: CRS without nasal polyps (CRS sine NP, CRSsNP) and CRS with nasal polyps (CRSwNP) [8, 26]. Clinically, the symptoms of both types are very similar to each other, with slight differences in the severity of nasal congestion, nasal obstruction, rhinorrhea, postnasal drip, change in the sense of smell, cough, and facial pain. In terms of physical examination, they differ by the presence or absence of nasal polyps extruding from the middle meatus of the nasal cavity. This simple difference noted by nasal endoscopy involves profound differences in cellular and molecular aspects that might be related to the prognosis and treatment of these two subsets of CRS.

Histologically, both forms of CRS are marked by niches of denuded respiratory epithelium with associated metaplasia, basal membrane thickening, and goblet cell hyperplasia. The histology of submucosal stroma demonstrates clear differences between CRSwNP and CRSsNP. In CRSwNP, the submucosal stroma usually is found with robust edema and low cellularity, in contrast to CRSsNP that characteristically involves more pronounced fibrosis and less edema [9].

In CRSwNP, eosinophilic infiltration is the hallmark of chronic inflammation. For reasons not fully elucidated, there is an increased expression of pro-inflammatory cytokines (IL-1 $\beta$ ) mediated by transcription factors. These cytokines mediate the recruitment of inflammatory cells (eosinophils, lymphocytes, neutrophils, mast cells) through the up-regulation and expression of adhesion molecules (ICAM-1, VCAM-1) and chemokines (IL-8, eotaxin, and RANTES). In CRSwNP, the striking influx of inflammatory cells, especially eosinophils, into the stroma, leads to a positive feedback recruitment similar to allergic rhinitis [27]. In the 
Caucasian CRS population, nasal polyps are remarkably characterized by a mixed expression of Th1 (INF- $\gamma$, IL-8) and Th2 cytokines, with an imbalance favoring the Th2 response. Th2 cytokines (IL-3, IL-5, GM-CSF) are produced by eosinophils and Th2 cells and increase eosinophil recruitment and survival, creating an autonomous inflammatory cycle even after the removal of the initial trigger. (Figure 2)

Transcription Factors

(NF-KB, STAT, NFAT, AP-1)

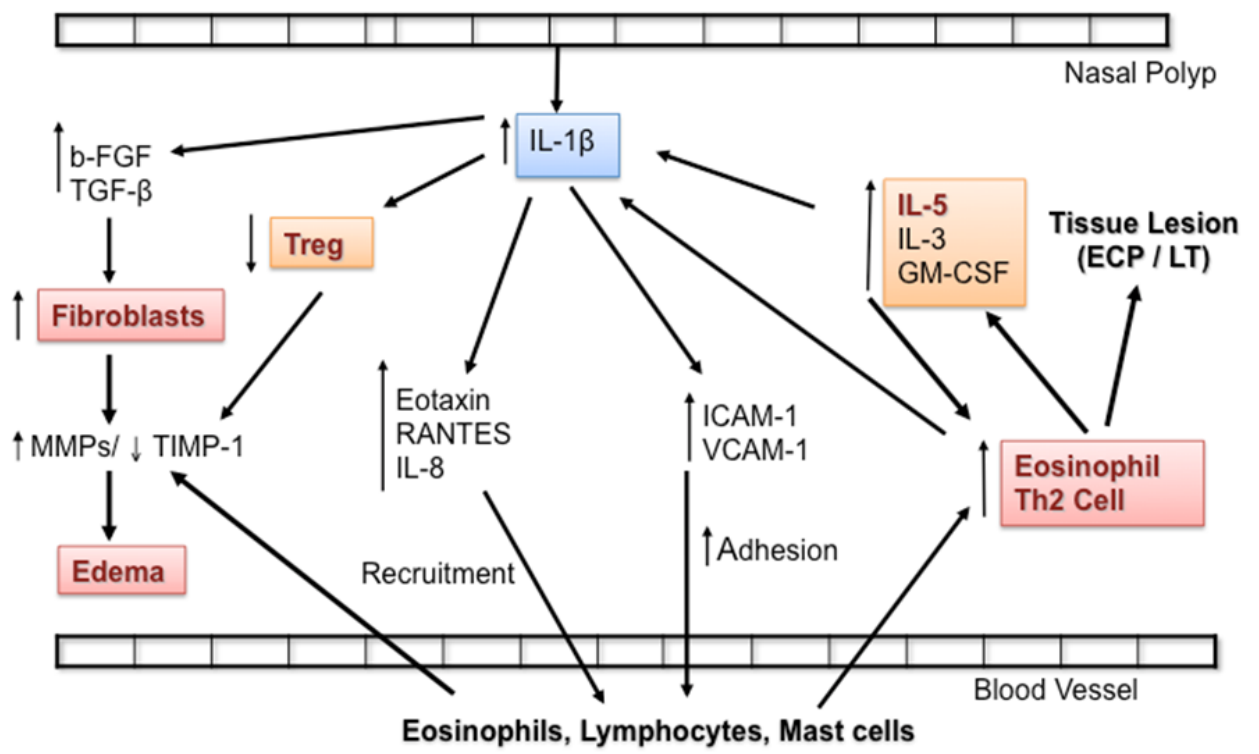

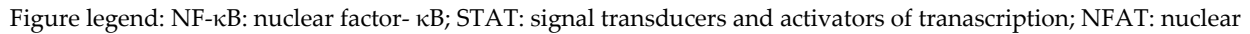
factor of activated T-cells; AP: activator protein; IL: interleukin; FGF: fibroblast growth factor; TGF: transforming growth factor; Treg: regulatory T cell; GM-CSF: granulocyte-macrophage colony-stimulating factor; ECP: eosinophil cationic protein; LT: leukotriene; MMP: matrix metalloproteinase; TIMP: tissue inhibitor of metalloproteinase; RANTES: regulated on activation, normal T cell expressed and secreted; ICAM: intercellular adhesion molecule; VCAM: vascular cell adhesion molecule; Th: T helper cell

Figure 2. Cellular and molecular events involved in the pathogenesis of CRSwNP.

Despite the similarities to allergic rhinitis and contrary to some speculations raised in the first studies, the eosinophilic infiltration and activation found in CRSwNP is not dependent on allergic mechanisms mediated by $\operatorname{IgE}[28,29]$. In the Chinese population, however, CRSwNP has been characterized by a different Th pattern of inflammation. A mixed Th1/Th17 has been found instead of the Th1/Th2 pattern, with a significantly lower GATA-3 (Th2 specific) expression and higher IL-17 levels in the polyp tissue. The Th17 response drives a more neutrophilic infiltration rather than an eosinophilic recruitment [30].

Another important feature of CRSwNP is the impaired regulatory modulation promoted by Treg cells, which balances the $\mathrm{T}$ helper cell response. Low levels of Treg cell biomarkers (transforming growth factor- $\beta 1$-TGF- $\beta 1$ - and forkhead box protein P3 -FOXP3) together 
with high expression of T-bet (Th1) and GATA-3 (Th2) demonstrate the deficiency of Treg control in CRSwNP patients [31].

In terms of molecular markers, among Caucasians, IL-5 is the most important cytokine found in CRSwNP. IL-5 is related to eosinophil infiltration and activation, and is significantly related to recurrence of nasal polyps after surgical removal [32]. Activated eosinophils also release several inflammatory mediators, such as leukotrienes, and other toxic products (Eosinophil Cationic Protein - ECP, Major Basic Protein - MBP, neurotoxin eosinophil protein). Besides the damage induced by infiltrated inflammatory cells, resident fibroblasts also play a role in the structural modification of the stroma. Stimulated by fibroblast growth factor (FGF) and TGF- $\beta$, fibroblasts are recruited, proliferate, and express matrix metalloproteinases (MMP), which degrade extracellular proteins (collagen, laminin, fibronectin, elastin) and favor tissue edema and albumin deposition. Other cells such as eosinophils and neutrophils are also able to produce MMP and may play a role in tissue remodeling [33]. Furthermore, fibroblasts suppress the expression of tissue inhibitors of metalloproteinases (TIMP) which increase the activity of MMP. Taken together, these features explain the main histopathological and molecular findings in CRSwNP, i.e., eosinophilic infiltration, tissue edema, and Th2 skewing polarization.

On the other hand, CRSsNP present some different features compared to CRSwNP. Although mixed inflammatory cells are found in CRSsNP, neutrophils are the predominant cells in this subset of CRS and, together with Th1 cells. seem to play the main cellular role in the pathogenesis of the disease. Neutrophil markers of activation such as myeloperoxidase and IL-8 are found in high levels in CRSsNP compared to controls and CRSwNP. Besides, the levels of Th1 cytokines (INF- $\gamma$, IL-8) found in CRSsNP are unbalanced with Th2 cytokines, revealing Th1 polarization. In contrast to CRSwNP, FOXP3 and TGF- $\beta$ are not decreased in CRSsNP, demonstrating that Treg function is not altered in CRSsNP [31]. The up-regulated TGF- $\beta$ signaling pathways are believed to be an important marker that reflects the fibrosis/albumin deposition remarkably seen in CRSsNP. (Figure 3)

In conclusion, in contrast to CRSwNP, the cellular and molecular findings in CRSsNP are characterized by neutrophilic infiltration, tissue fibrosis, and Th1 skewing polarization.

\section{Glucocorticoid action on nasal mucosa}

Glucocorticoid (GC) has a broad anti-inflammatory effect, regulating both innate and adaptive immune responses in a wide variety of cells, such as epithelial cells, fibroblasts, eosinophils and T cells $[1,12,34]$. This is the main reason why GC is considered to be the medication of choice to treat chronic rhinitis [2] and rhinosinusitis [8].

This wide anti-inflammatory effect of GC is explained by several events induced by it, from the signaling event to post-translational mechanisms. Basically, GC is a lipophilic compound which diffuses though the membrane and binds to its cytoplasmic receptor, called glucocorticoid receptor (GR) [35]. 


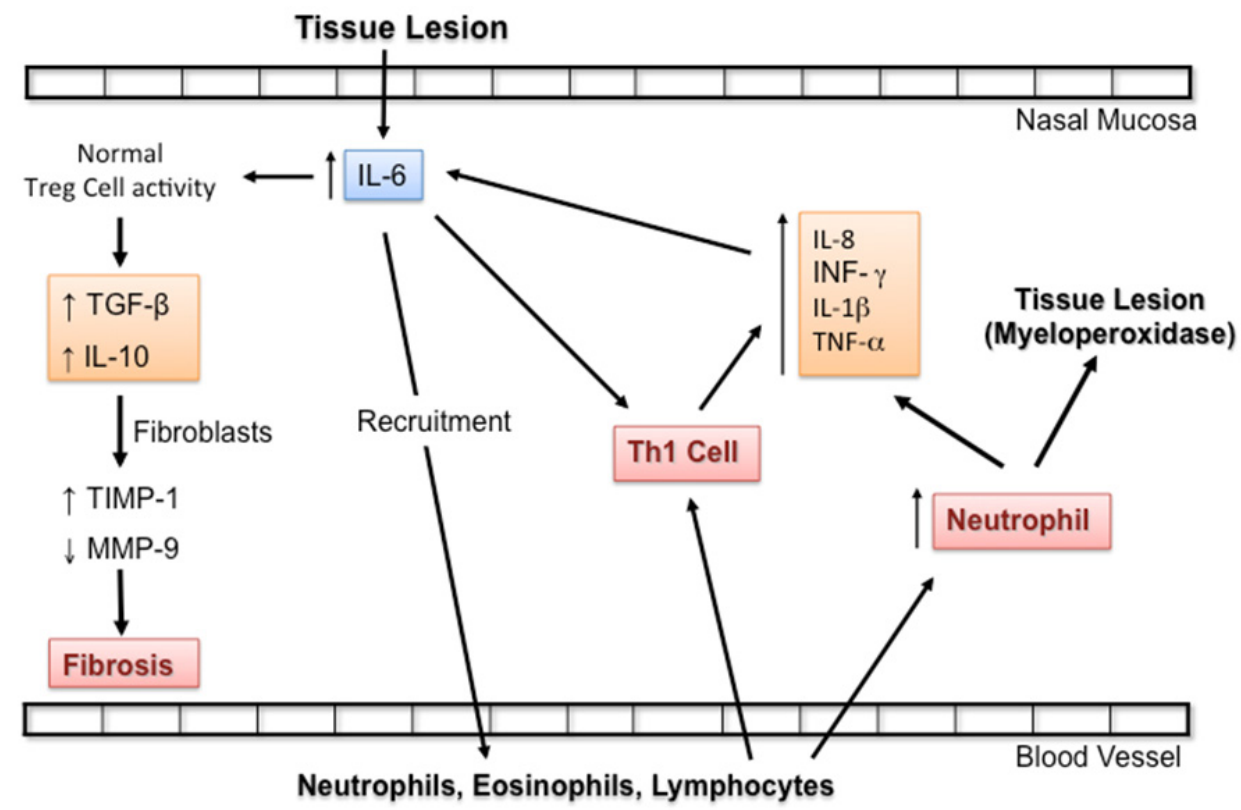

Figure legend: Treg: regulatory T cell; IL: interleukin; INF: interferon; TNF: tumor necrosis factor; Th: T helper cell; TGF: transforming growth factor; TIMP: tissue inhibitor of metalloproteinase; MMP: metalloproteinase

Figure 3. Cellular and molecular events involved in the pathogenesis of CRSsNP.

GR belongs to a large superfamily of steroid receptors. When inactivated, this receptor stays in the cytosol bound to heat shock proteins (hsp) [36]. When GC binds to GR, phosphorylation occurs to this receptor, which dissociates GR from hsp. The dimer GC-GR is able to translocate into the nucleus and then act as a transcription factor. In this respect, the GC-GR dimer can bind directly to a specific palindromic DNA consensus sequence, called glucocorticoid response elements (GREs), and consequently induces or inhibits (in case of nGREs) the transcription of several genes [35]. Nevertheless, it is recognized that the main anti-inflammatory action of GC at the transcriptional level is mediated by a direct interaction of GC-GR with other transcription factors (TF), inhibiting their action. This inhibition, called "DNA-independent transrepression" affects several pro-inflammatory TF, the most important ones being activator protein-1 (AP-1) and nuclear fator- $\kappa \mathrm{B}(\mathrm{NF}-\kappa \mathrm{B})[1$, 35-39] (Figure 4). This connection inhibits gene transcription by direct binding to DNA or by inducing histone deacetylation. Although the non-genomic effect of GC is widely known in the literature $[2,17]$, there is no report on its effect on chronic upper respiratory diseases, and only few studies have reported controversial results regarding asthma [40, 41].

The final effect of GC on nasal diseases is the inhibition of pro-inflammatory cytokines (IL$1 \beta$, TNF- $\alpha$, GM-CSF, IL-3, IL-5, IL-6), chemokines (IL-8, RANTES, eotaxin) and adhesion molecules (VCAM-1, ICAM-1) [1, 13, 42]. Glucocorticoids also have a favorable effect on tissue remodeling (reducing MMP expression) [43, 44], reduce mucin production [45], increase cell apoptosis [46, 47], and decrease mast cell recruitment and activation [48]. 
Finally, glucocorticoids inhibit the expression of some cytokine receptors, among them IL-2 and IL-4 receptors.

Due to its holistic action, GC is considered to be the best medication for the treatment of chronic inflammatory diseases of the upper respiratory airways.

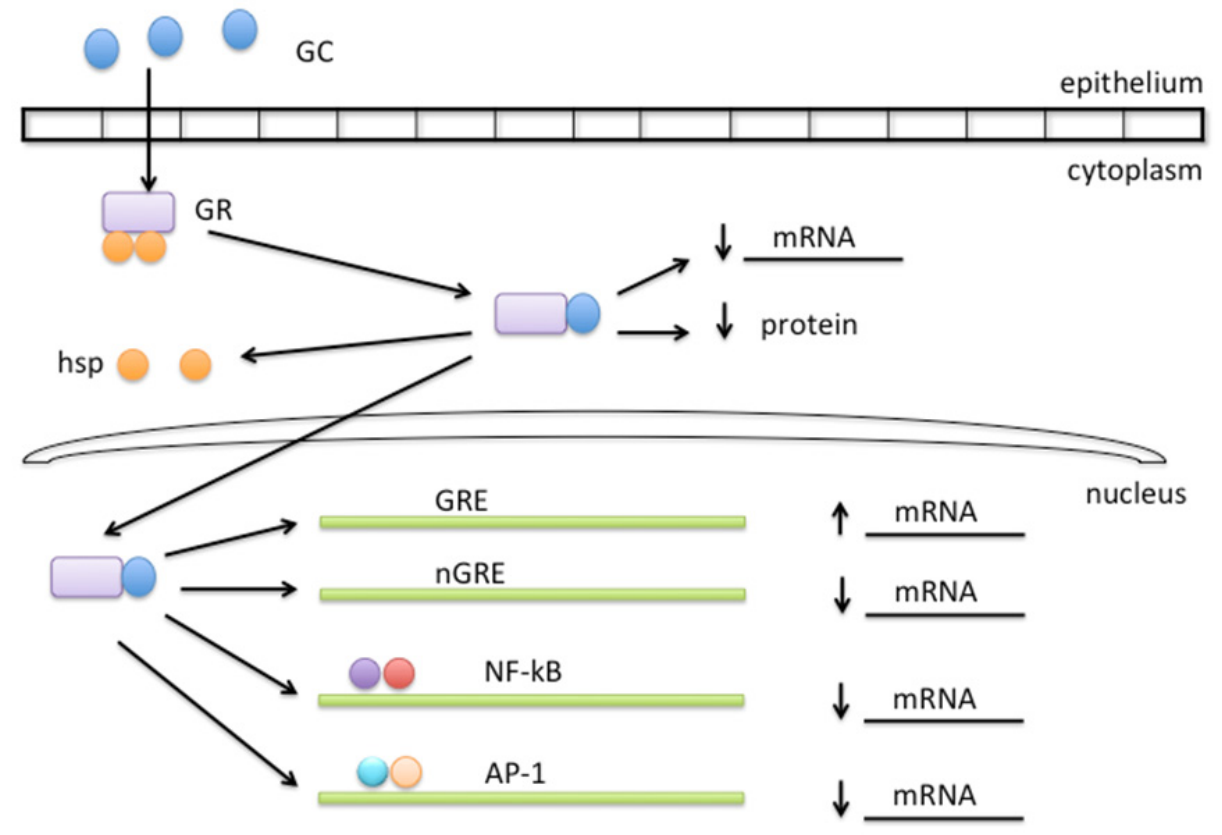

Figure 4. GC mode of action: binding to its cytoplasmic GR, and then translocating into the nucleus. GC: glucocorticoid; GR: glucocorticoid receptor; hsp: heat shock protein; GRE: glucocorticoid response

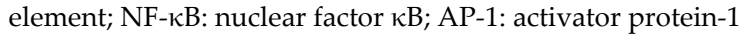

\section{GR splicing}

The GR gene is located in chromosome 5 and is composed of 9 exons. Alternative splicing in the ninth exon (hormone-binding domain) gives raise to several alternative GRs, GR $\alpha$ and GR $\beta$ being the most common [35-39].

GR $\alpha$ is the predominant GR isoform. It is transcriptionally active and, when ligated to GC, it can translocate into the nucleus, induce expression by binding to GRE, or repress expression by either binding to nGRE or by interacting with AP-1 and NF- $\kappa \mathrm{B}[1,35,36]$.

For instance, GR $\beta$ is expressed at much lower rates than GR $\alpha$. It cannot bind to GC, and although it can bind to GRE, nGRE, AP-1 and NF- $\kappa B$, it does not activate their transcriptional action. Some authors have shown that, when overexpressed, GR $\beta$ inhibits the effect of GR $\alpha$ on both transactivation and on AP-1 and NF- $\kappa B$ repression [49-51]. GR $\beta$ is thus considered to be the dominant negative of GR $\alpha$; instead, a recent study has shown that 
a glucocorticoid antagonist, named RU-486, has the ability to bind to GR $\beta$, regulating gene expression even in the absence of GR $\alpha$ [52].

There is no previous study regarding the influence of GR $\gamma$ on nasal mucosa.

\section{Resistance to GC}

Although GC is the medication of choice in chronic upper respiratory diseases in general, the rate of CG therapy failure in CRSwNP is reported to be between 60 and $80 \%$ [8]. Although there is no report on GC resistance in chronic rhinitis, resistance is believed to be identical to that occurring in CRSwNP. The main reasons for GC failure are: limited action of topical GC in extensive diseases [53], poor compliance with treatment [54], and cellular/molecular resistance to GC $[36,55]$. Among cellular and molecular mechanisms of GC resistance, the main lines investigated are GR $\alpha$ - GR $\beta$ interaction and TF influence.

One of the most studied mechanisms is the GR $\alpha$-GR $\beta$ imbalance. Although GR $\beta$ is able to interact directly with GR $\alpha$ within the nucleus, it has a low capacity to bind to GC. This is why GR $\beta$ is considered to be an endogenous inhibitor of GR $\alpha$ [36, 56]. GR $\alpha$-GR $\beta$ imbalance has been reported to increase cell resistance in chronic immune-mediated diseases, among those affecting the upper [37, 57] and lower airways [58, 59].

Increased expression of GR $\beta$ has been widely reported in the literature on inflammatory respiratory diseases such as CRSwNP and asthma, when compared to control mucosa [36, $55,60,61]$. This has led to the hypothesis that increased GR $\beta$ expression could impair the action of GC. Decreased expression of GR $\alpha$ has also been recently reported in CRswNP with the use of a more reliable quantitative method of analysis [56, 62, 63]. More important than the expression of each individual isoform, GR $\alpha$-GR $\beta$ imbalance might be the most relevant determinant of GC resistance. It is important to mention that some studies have demonstrated that CG therapy in CRSwNP does not change GR isoform expression or the GR $\alpha$-GR $\beta$ relation $[56,63,64]$.

Higher expression of TF could also lead to GC resistance, because TF (mainly AP-1 and NF$\mathrm{\kappa B}$ ) repress the binding of the translocated GC-GR complex to GRE. This mechanism of GC resistance has been reported in several inflammatory diseases, such as inflammatory bowel diseases. Nevertheless, this mechanism has been poorly reported in respiratory diseases.

AP-1 is a dimer predominantly consisting of c-Fos/c-Jun heterodimers. As is the case for most TF, they are located in the cytoplasm and, when activated, translocate into the nucleus and induce the expression of several pro-inflammatory genes which regulate cell inflammation, proliferation, differentiation and apoptosis [65]. Conflicting results have been reported regarding the presence of AP-1 in CRSwNP. c-Fos expression has been studied in two reports because it is more important regarding the transcriptional action. One study [66] has reported an increased presence of c-Fos in patients with CRSwNP than in control mucosa using qualitative PCR, while the other [56] has observed a similar expression in the two groups using quantitative RT-PCR. The latter study also did not observe any influence of c-Fos expression on the outcome of GC treatment. 
NF- $\kappa \mathrm{B}$ is also a heterodimer, mainly consisting of p50 and p65 isoforms. When activated, NF- $\kappa \mathrm{B}$ translocates into the nucleus, and p65 directly binds to DNA, inducing gene expression of pro-inflammatory and anti-apoptotic genes [37, 65]. NF- $\kappa \mathrm{B}$ is considered pivotal to the regulation of immune and inflammatory genes, and its absence is incompatible with life. It is important to mention that the most important pro-inflammatory cytokines (IL-1 $\beta$ and TNF- $\alpha$ ), whose expression is considerably influenced by NF- $\kappa \mathrm{B}$, also activate NF- $\kappa \mathrm{B}$ translocation, inducing perpetuation of the inflammatory process.

Two studies have reported increased expression of both isoforms ( $\mathrm{p} 50$ and p65) of NF- $\mathrm{kB}$ in patients with CRSwNP when compared to control nasal mucosa [56, 67]. Also, a high expression of p65 was related to a poor clinical outcome in response to medical treatment in CRSwNP patients [56]. This finding suggests that NF- $\kappa B$ may also have a pivotal effect on GC resistance.

\section{Conclusions}

Chronic inflammatory nasal diseases are highly prevalent in the population, and therefore nasal TGC has been widely prescribed by physicians. Considering that a high percentage of these patients only partially benefit from TGC, or do not respond to TCG treatment at all, the understanding of possible mechanisms of GC resistance is essential for future treatments.

Today, it has been accepted that cellular and molecular mechanisms of resistance do exist in nasal mucosa. Future investigations are still required to recognize affected individuals and how this would influence medical treatment. This will be essential to develop new drugs that would replace or act synergistically with CG, in order to improve the clinical outcome.

\section{Author details}

Fabiana C.P. Valera, Edwin Tamashiro and Wilma T. Anselmo-Lima

Division of Otorhinolaryngology, Departament of Ophthalmology, Otorhinolaryngology, and Head and Neck Surgery. Faculty of Medicine of Ribeirao Preto-University of São Paulo, Ribeirao Preto-SP, Brazil

\section{References}

[1] Stellato, C., Glucocorticoid actions on airway epithelial responses in immunity: Functional outcomes and molecular targets. J Allergy Clin Immunol 2007. 120(6): p. 1247-63.

[2] Bousquet J, K.N., Cruz AA, Denburg J, Fokkens WJ, Togias A, et al, Allergic Rhinitis and its impact on asthma (ARIA) 2008. Allergy 2008. 63: p. 8-160. 
[3] Bauchau V, D.S., Prevalence and rate of diagnosis of allergic rhinitis in Europe. Eur R Espir J, 2004. 24: p. 758-764.

[4] Collins, J., Prevalence of selected chronic conditions: United States 1990-1992. Vital Health Stat, 1997. 194: p. 1-89.

[5] Bentley AM, J.M., Cumberworth V, Barkans JR, Moqbel R, Schwartz LB, et al. , Immunohistology of the nasal mucosa in seasonal allergic rhinitis: increases in activated eosinophils and epithelial mast cells. J Allergy Clin Immunol, 1992. 89: p. 877- 883 .

[6] Laliberte F, L.M., Lecart S, Bousquet J, Klossec JM, Mounedji N, Clinical and pathologic methods to assess the long-term safety of nasal corticosteroids. French Triamcinolone Acetonide Study Group. . Allergy, 2000. 55(718-722).

[7] Shaida A, K.G., Devalia J, Davies RJ, MacDonald TT, Pender SL, Matrix metalloproteinases and their inhibitors in the nasal mucosa of patients with perennial allergic rhinitis. J Allergy Clin Immunol 2001. 108(5): p. 791-796.

[8] Fokkens WJ, L.V., Mullol J, Bachert C, Cohen N, Cobo R, et al. European Position Paper on Nasal Polyps 2007. Rhinology 2007, 20: 1-139., European Position Paper on Nasal Polyps 2007. Rhinology, 2007. 20: p. 1-139.

[9] Huvenne W, v.B.N., Zhang N, van Zele T, Patou J, Gevaert P, et al, Chronic Rhinosinusitis With and Without Nasal Polyps: What Is the Difference? Curr Allergy Asthma Rep, 2009. 9: p. 213-220.

[10] Jankowski R, B.F., Coffinet L, Vignaud JM, Clinical factors influencing the eosinophil infiltration of nasal polyps. Rhinology, 2002. 40: p. 173-8.

[11] Pawankar R, M.S., Ozu C, Kimura S, Overview on the pathomechanisms of allergic rhinitis. Asia Pac Allergy, 2011. 1(3): p. 157-167.

[12] Bradding P, O.Y., Howarth PH, Church MK, Holgate ST, Heterogeneity of human mast cells based on cytokines content. J Immunol, 1995. 155: p. 297-307.

[13] Kawabori Y, K.N., Tosho T, Proliferative activity of mast cells in allergic nasal mucosa. Clin Exp Allergy 1995. 25: p. 173-8.

[14] Baraniuk, J., Pathogenesis of allergic rhinitis. J Allergy Clin Immunol 1997. 99: p. S763S772.

[15] Eccles, R., Pathophysyology of Nasal Symptoms. Am J Rhinol 2000. 14(5): p. 335-338.

[16] McDonald, D., Neurogenic inflammation in the respiratory tract: actions of sensory nerve mediators on blood vessels and epithelium of the airway mucosa. Am Rev Respir Dis, 1987. 136(6 Pt 2): p. S65-S72.

[17] Gosset P, M.F., Delnest Y, et al., Interleukin 6 and interleukin-1 $\alpha$ production is associated with antigen induced late nasal response. J. Allergy Clin. Immunol., 1993. 94(11777-11783).

[18] Naclerio RM, B.F., Kagey-Sobotka A, Lichtenstein LM, Basophils and eosinophils in allergic rhinitis. J Allergy Clin Immunol, 1994. 94(6 Pt 2): p. 1303-1309.

[19] Moqbel R, L.-S.F., Kay AB, Cytokine generation by eosinophils. J Allergy Clin Immunol 1994. 94(6 Pt 2): p. 1183-9. 
[20] Pawankar RU, O.M., Okubo K, Ra C, Lymphocyte subsets in the nasal mucosa in perennial allergic rhinitis. Am J Respir Crit Care Med, 1995. 152(6 Pt 1): p. 2049-58.

[21] Nonaka M, N.R., Jordana M, Dolovich J, GM-CSF, IL-8, IL-1R, TNF-alpha R, and HLADR in nasal epithelial cells in allergic rhinitis. Am J Respir Crit Care Med, 1996. 153(5): p. $1675-81$.

[22] Kenney JS, B.C., Welch MR, Altman LC, Synthesis of interleukin-1 alpha, interleukin-6, and interleukin-8 by cultured human nasal epithelial cells. J Allergy Clin Immunol, 1994. 93(6): p. 1060-7.

[23] Ziegler SF, A.D., Sensing the outside world: TSLP regutates barrier immunity. Nat Immunol, 2010. 11: p. 289-293.

[24] Miyata M, N.Y., Shimokawa N, Ohnuma Y, Katoh R, Matsuoka S, Okumura K, Ogawa H, Masuyama K, Nakao A, Thymic stromal lymphopoietin is a critical mediator of IL13-driven allergic inflammation. Eur J Immunol, 2009. 39(11): p. 3078-83.

[25] Masuda, S., Quantitative histochemistry of mucus-secreting cells in human nasal mucosa. . Pract Otol (Kyoto), 1990. 83: p. 1855-63.

[26] Van Zele T, C.S., Gevaert P, Van Maele G, Holtappels G, VanCauwenberge P, Bachert C, Differentiation of chronic sinus diseases by measurement of inflammatory mediators. Allergy 2006. 61(11): p. 1280-1289.

[27] Bachert C, G.P., Holtappels G, Cuvelier C, van Cauwenberge P, Nasal polyposis: from cytokines to growth. Am J Rhinol, 2000. 14(279-290).

[28] Min YG, L.C., Rhee CS, Kim KH, Kim CS, Koh YY, Min KU, Anderson PL, Inflammatory cytokine expression on nasal polyps developed in allergic and infectious rhinitis. Acta Otolaryngol, 1997. 117(2): p. 302-6.

[29] Lee CH, R.C., Min YG, Cytokine gene expression in nasal polyps. Ann Otol Rhinol Laryngol 1998. 107(8): p. 665-70.

[30] Zhang N, H.G., Claeys C, Huang G, van Cauwenberge P, Bachert C, Pattern of inflammation and impact of Staphylococcus aureus enterotoxins in nasal polyps from southern China. Am J Rhinol, 2006. 20(4): p. 445-450.

[31] Van Bruaene N, P.-N.C., Basinski TM, Van Zele T, Holtappels G, De Ruyck N, SchmidtWeber C, Akdis C, Van Cauwenberge P, Bachert C, et al, T-cell regulation in chronic paranasal sinus disease. J Allergy Clin Immunol, 2008. 121(6): p. 1435-1441, 1441. 1441.e1-e3.

[32] Bachert C, W.M., Hauser U, Rudack C, IL-5 synthesis is upregulated in human nasal polyp tissue. J Allergy Clin Immunol, 1997. 99: p. 837-842.

[33] Delclaux C, D.C., D’Ortho MP, Boyer V, Lafuma C, Harf A, Role of gelatinase B and elastase in human polymorphonuclear neutrophil migration across basement membrane. Am J Respir Cell Mol Biol, 1996. 14: p. 288-295.

[34] Holm AF, F.W., Godthelp T, Mulder PG, Vroom TM, Rjintejes E, Effect of 3 month's nasal steroid therapy on nasal $\mathrm{T}$ cells and Langerhans cells in patients suffering from allergic rhinitis. Allergy 1995. 50: p. 204-209. 
[35] Liberman AC, D.J., Perone MJ, Arzt E, Glucocorticoids in the regulation of transcription factors that control cytokine synthesis. Cytokine Growth Factor Rev, 2007. 18(1-2): p. 4556.

[36] Pujols L, M.J., Picado C, Alpha and beta glucocorticoid receptors: relevance in airway diseases. Curr Allergy Asthma Rep, 2007. 7(2): p. 93-99.

[37] Adcock IM, C.G., Cross-talk between pro-inflammatory transcription factors and glucocorticoids. Immunol Cell Biol, 2001. 79: p. 376-384.

[38] Li Q, V.I., NF-[kappa]B regulation in the immune system. Nat Rev Immunol, 2002. 2: p. 725-734.

[39] McKay LI, C.J., Molecular control of immune/inflammatory responses: interactions between nuclear factor-kappaB and steroid receptor-signaling pathways. Endocr Rev, 1999. 20(4): p. 435-459.

[40] Stellato, C., Post-transcriptional and nongenomic effects of glucocorticoids Proc Am Thorac Soc, 2004. 1(3): p. 255-263.

[41] Urbach V, V.V., Grumbach Y, Bousquet J, Harvey BJ, Rapid anti-secretory effects of glucocorticoids in human airway epithelium. Steroids, 2006. 71(4): p. 323-328.

[42] Valera FCP, B.M., Castro-Gamero AM, Cortez MA, Rosane GP Queiroz, Luiz G Tone, Anselmo-Lima, In vitro effect of glucocorticoids on nasal polyps. Braz J Otorhinolaryngol, 2011. 77(5): p. 605-610.

[43] Kyo Y, K.K., Asano K, Hisamitsu T, Suzaki H, Supressive effect of fluticasone propionate on MMP expression in the nasal mucosa of allergic rhinitis patients in vivo. . In Vivo 2006. 20: p. 439-444.

[44] Yigit O, A.E., Gelisgen R, Server EA, Azizli E, Uzun H, The effect of corticosteroid on metalloproteinase levels of nasal polyposis. Laryngoscope 2011. 121(3): p. 667-673.

[45] Bal CH, S.S., Kim YD, Effect of glucocorticoid on the MUC4 gene in nasal polyps. Laryngoscope 2007. 117: p. 2169-2173.

[46] Bobic S, v.D.C., Callebaut I, Hox V, Jorissen M, Fokkens WJ, et al, Dexamethasoneinduced apoptosis of freshly isolated human nasal epithelial cells concomitant with abrogation of IL-8 production. Rhinology 2010. 48: p. 401-407.

[47] Hirano S, A.K., Namba M, Kanai K, Hisamitsu T, Suzaki H, Induction of apoptosis in nasal polyps fibroblasts by glucocorticoids in vitro. Acta Otolaryngol, 2003. 123(10751079).

[48] Juluisson S, A.F.E.L.P.c.o.m.c.o.n.m.e.o.n.a.a.o.l.c.t.A., 50:15-22, Protease content of mast cells of nasal mucosa: effects of natural allergen and of local corticosteroid treatment. . Allergy 1995. 50: p. 15-22.

[49] Lu NZ, C.J., Grissom SF, Cidlowski JA, Selective regulation of bone cell apoptosis by translational isoforms of the glucocorticoid receptor. Mol Cell Biol, 2007. 27(20): p. 7143-7160.

[50] Bamberger CM, B.A., de Castro M, Chrousos GP, Glucocorticoid receptor $\beta$, a potential endogenous inhibitor of glucocorticoid action in humans. J Clin Invest, 1995. 95: p. 2435-2441. 
[51] Gougat C, J.D., Gagliardo R, Henriquet C, Bousquet J, Demoly P, Mathieu M, Overexpression of the human glucocorticoid receptor $\alpha$ and $\beta$ isoforms inhibits AP-1 and NF- $\kappa$ B activities hormone independently. J Mol Med, 2002. 80: p. 309-318.

[52] Lewis-Tuffin LJ, J.C., Bienstock RJ, Collins JB, Cidlowski JA Human glucocorticoid receptor beta binds RU-486 and is transcriptionally active. Mol Cell Biol, 2007. 27(22662282).

[53] Valera FCP, A.-L.W., Evaluation of efficacy of topical corticosteroid for the clinical treatment of nasal polyposis: searching for clinical events that may predict response to treatment. . Rhinology 2007. 45(1): p. 59-62.

[54] Badia L, L.V., Topical corticosteroids in nasal polyposis. Drugs 2001. 61: : p. 573-578.

[55] Hamilos DL, L.D., Muro S, Kahn AM, Hamilos SS, Thawley SE, et al., GR $\beta$ expression in nasal polyp inflammatory cells and its relationship to the anti-inflammatory effects of intranasal fluticasone. J Allergy Clin Immunol, 2001. 108: : p. 59-68.

[56] Valera FCP, Q.R., Scrideli C, Tone LG, Anselmo-Lima WT, NF- $\kappa B$ expression predicts clinical outcome for nasal polyposis. Rhinology 2010. 48(4): p. 408-414.

[57] Valera FCP, Q.R., Scrideli C, Tone LG, Anselmo-Lima WT, Evaluating budesonide efficacy in nasal polyposis and predicting the resistance to treatment. Clin Exper Allergy, 2009. 39(1): p. 81-88.

[58] Gagliardo R, C.P., Vignola AM, Bousquet J, Vachier I, Godard P, Bonsignore G, Demoly $\mathrm{P}$, Mathieu M, Glucocorticoid Receptor $\alpha$ and $\beta$ in glucocorticoid dependent asthma. Am J Respir Crit Care Med, 2000. 162: p. 7-13.

[59] Barnes, P., Corticosteroid resistance in airway disease. Proc Am Thorac Soc 2004(1): p. 264-268.

[60] Pujolsa L, M.J., Picado C, Glucocorticoid Receptor in Human Respiratory Epithelial Cells. Neuroimmunomodul, 2009. 16(5): p. 290-299.

[61] Sousa AR, L.S., Cidlowski JA, Staynov DZ, Lee TH, Glucocorticoid resistance in asthma is associated with elevated in vivo expression of the glucocorticoid receptor $\beta$-isoform. J Allergy Clin Immunol, 2000. 105(5): p. 943-950.

[62] Li P, L.Y., Zhang X, Zhang G, Ye J, Sun Y, et al., Detection of glucocorticoid receptoralpha mRNA expression using FQ-RT-PCR in nasal polyp. Lin Chuang Er Bi Yan Hou Ke Za Zhi, 2005. 19(769-771).

[63] Pujols L, A.I., Benítez P, Martínez-Antón A, Roca-Ferrer J, Fokkens WJ, Mullol J, Picado C, Regulation of glucocorticoid receptor in nasal polyps by systemic and intranasal glucocorticoids. Allergy 2008. 63(10): p. 1377-1386.

[64] Choi BR, K.J., Gong SJ, Kwon MS, Cho JH, Kim JH, et al, Expression of glucocorticoid receptor mRNAs in glucocorticoid-resistant nasal polyps. Exp. Mol. Med, 2006. 38: p. 466-473.

[65] Necela BM, C.J., Mechanisms of glucocorticoid receptor action in noninflammatory and inflammatory cells. Proc Am Thorac Soc, 2004. 1(3): p. 239-246.

[66] Baraniuk JN, W.G., Ali M, Sabol M, Troost T, Glucocorticoids decrease c-fos expression in human nasal polyps in vivo. Thorax 1998. 53: p. 577- 582. 
[67] Takeno S, H.K., Ueda T, et al, Nuclear factor-kappa B activation in the nasal polyp epithelium: relationship to local cytokine gene expression. Laryngoscope 2002. 112(1): p. 53-58 